\title{
Indutores de resistência no controle da pinta bacteriana do tomateiro e na atividade de enzimas de defesa
}

\author{
Camila C.L. Andrade1, Renata S. Resende², Fabrício A. Rodrigues², Patrícia R. Silveira², Jonas A. Rios², \\ José R. Oliveira² \& Rosa L.R. Mariano ${ }^{1}$
}

${ }^{1}$ Departamento de Fitopatologia, Universidade Federal Rural de Pernambuco, 52171-900, Recife, PE, Brazil; ${ }^{2}$ Departamento de Fitopatologia, Universidade Federal de Viçosa, 36570-000, Viçosa, MG, Brazil

Autor para correspondência: Fabrício A. Rodrigues, e-mail: fabricio@ufv.br

\section{RESUMO}

Em três experimentos, avaliou-se o efeito de pulverizações de ácido jasmônico (AJ), etefon (ET) e acibenzolar-S-metil (Bion ${ }^{\circledR}$ ) (ASM) a $0,1 \mathrm{mM}, 0,5 \mathrm{mM}$ e $0,3 \mathrm{~g} \mathrm{~L}^{-1}$, respectivamente, nos componentes de resistência do tomateiro (cv. Santa Clara) à pinta bacteriana, causada por Pseudomonas syringae pv. tomato e na atividade de peroxidases (POX), polifenoloxidases (PFO), $\beta$-1,3-glucanases (GLU) e lipoxigenases (LOX). Apenas no experimento 3, o período de incubação aumentou significativamente em um dia nas plantas pulverizadas com ASM, em comparação com as plantas pulverizadas com água (controle). O número de lesões por planta foi significativamente reduzido por AJ, ET e ASM nos três experimentos. Para algumas épocas de avaliação, a atividade de POX, PFO e GLU foram maiores para o AJ; de PFO, GLU e LOX, para o ASM; e de GLU e LOX, para o ET em comparação com o controle. Conclui-se que na presença de AJ, ET e ASM, os sintomas da pinta bacteriana foram reduzidos e a atividade das enzimas POX, PFO, GLU e LOX foram maiores.

Palavras-chave: Pseudomonas syringae pv. tomato, Solanum lycopersicum, ácido jasmônico, acibenzolar-S-metil, etileno.

\begin{abstract}
Inducers of resistance on the control of tomato bacterial speck and on the activity of defense enzymes

Three experiments were performed aimed to evaluate the effect of jasmonic acid (JA), ethephon (ET) and acibenzolar-S-methyl $\left(\right.$ Bion $\left.^{\circledR}\right)(\mathrm{ASM})$ sprayed at $0.1 \mathrm{mM}, 0.5 \mathrm{mM}$ and $0.3 \mathrm{~g} \mathrm{~L}^{-1}$, respectively, on the components of resistance of tomato plants (cv. Santa Clara) to bacterial speck caused by Pseudomonas syringae pv. tomato as well as on the activity of peroxidases (POX), polyphenoloxidases (PPO), $\beta$-1,3-glucanases (GLU) and lypoxigenases (LOX). Only for experiment 3, the incubation period significantly increased by one day for plants sprayed with ASM compared to plants sprayed with water (control). For all experiments, the number of lesions per plant was significantly reduced by JA, ET and ASM in comparison to the control. For some evaluation times, POX, PPO and GLU activities were higher for JA; PFO, GLU and LOX for ASM; and GLU and LOX for ET in comparison to the control. In conclusion, in the presence of AJ, ET and ASM, bacterial speck symptoms were reduced and the activity of the enzymes POX, PFO, GLU and LOX increased.
\end{abstract}

Key words: Pseudomonas syringae pv. tomato, Solanum lycopersicum, acibenzolar-S-methyl, ethephon, jasmonic acid.

\section{INTRODUÇÃO}

A pinta bacteriana, causada por Pseudomonas syringae pv. tomato (Pst) é uma doença economicamente importante para a cultura do tomateiro. Em condições de temperatura entre 20 e $25^{\circ} \mathrm{C}$ e alta umidade, a doença pode causar perdas de até 30\% na produção (Silva \& Lopes, 1995).

Para o controle da pinta bacteriana, recomendase utilizar variedades com resistência conferida pelo gene Pto e evitar o plantio de mudas com sintomas da doença, principalmente, nos períodos mais propícios à sua ocorrência (Stockinger \& Walling, 1994; Silva et al., 2002). O controle de doenças bacterianas é limitado quanto à disponibilidade de produtos químicos; atualmente apenas um produto à base de oxicloreto de cobre e o indutor de resistência acibenzolar-S-metil, conhecido comercialmente como Bion ${ }^{\circledR}$, são registrados no Ministério da Agricultura, Pecuária e Abastecimento (MAPA, 2007).
A busca por formas de controle de doenças que apresentem redução do uso de agroquímicos e a conscientização da população acerca dos problemas ambientais vêm se destacando e promovendo segurança alimentar, sustentabilidade e, principalmente, o manejo fitossanitário. O uso de produtos comerciais que induzem resistência vem ganhando relevância no controle de doenças de plantas. Dentre eles, destaca-se o acibenzolarS-metil (ASM) que atua em várias espécies vegetais contra uma ampla gama de patógenos, incluindo fungos, vírus e bactérias (Görlach et al., 1996). Este indutor de resistência possibilita proteção em tomateiros contra Pst (Scarponi et al., 2001), Clavibacter michiganensis subsp. michiganensis (Baysal et al., 2003) e Xanthomonas campestris pv. vesicatoria (Cavalcanti et al., 2006ab).

Diversos mecanismos podem ser ativados durante o fenômeno de indução de resistência, entre os quais a síntese de metabólitos secundários tóxicos aos patógenos, espécies 
reativas de oxigênio e ativação de genes que codificam proteínas relacionadas à patogênese (proteínas-PR), como $\beta$-1,3-glucanases e quitinases (Van Loon, 1997). O ácido salić́lico (AS), jasmonatos e etileno têm sido relatados como elementos sinalizadores envolvidos com as respostas de defesa específicas dentro das células (Kunkel \& Brooks, 2002). O ASM é um análogo ao AS que, juntamente com o ácido jasmônico (AJ) e o etefon (2-cloroetil fosfônico) (ET), utilizado como liberador de etileno, induzem a ativação de genes que codificam para a biossíntese de enzimas relacionadas à produção de fitoalexinas que são compostos tóxicos aos patógenos, possibilitando aumento da resistência das plantas (Lamb \& Dixon, 1997; Yahia et al., 1998).

Para o patossistema tomateiro-Pst existem poucos trabalhos evidenciando o efeito dos indutores de resistência na redução dos sintomas da pinta bacteriana, bem como na atividade de enzimas de defesa. Assim, o objetivo deste estudo foi avaliar o efeito da pulverização dos indutores ASM, AJ e ET em alguns componentes de resistência do tomateiro à pinta bacteriana e na atividade de enzimas envolvidas com a defesa da planta.

\section{MATERIAL E MÉTODOS}

\section{Obtenção do isolado de Pseudomonas syringae pv. tomato}

O isolado de Pst foi obtido de plantas de tomateiro com sintomas de pinta bacteriana em plantio comercial no município de Coimbra ( $\mathrm{MG}$ ) e preservado em óleo mineral e água destilada esterilizada (Mariano \& Assis, 2005). A identidade do isolado foi confirmada por teste de patogenicidade em tomateiro, testes LOPAT (levana + oxidase + podridão em batata + arginina + hipersensibilidade em tabaco) (Schaad, 1988) e sequenciamento do gene 16S rRNA.

Para utilização nos experimentos, o isolado de $P s t$ foi cultivado em meio Kado 523 (Kado \& Heskett, 1970) (sacarose $10 \mathrm{~g}$, caseína ácida hidrolisada $8 \mathrm{~g}$, extrato de levedura $4 \mathrm{~g}, \mathrm{~K}_{2} \mathrm{HPO}_{4} 2 \mathrm{~g}, \mathrm{MgSO}_{4} \cdot 7 \mathrm{H}_{2} \mathrm{O} 0,3 \mathrm{~g}$, ágar $15 \mathrm{~g}$, água destilada $1000 \mathrm{~mL}$ ), pelo método de estrias, por 24 horas a $28^{\circ} \mathrm{C}$. Após este período, solução salina $0,85 \%$ foi adicionada em cada placa de Petri contendo o crescimento bacteriano e a concentração da suspensão foi ajustada em fotocolorímetro (Analyser ${ }^{\circledR}$ ) a $540 \mathrm{~nm}$ de absorbância $\left(\mathrm{A}_{540 \mathrm{~nm}}\right)$ de acordo com equação pré-estabelecida, em que $\mathrm{A}_{540}=0,20$ equivale a $1,0 \times 10^{8} \mathrm{UFC} \mathrm{mL}^{-1}$.

\section{Plantio}

Sementes de tomateiro da cultivar Santa Clara, cedidas pela empresa Sakata Seed Sudamerica (Bragança Paulista, SP), foram semeadas em número de seis sementes por vaso contendo $2 \mathrm{~kg}$ de uma mistura de solo esterilizado, húmus e areia na proporção 3:1:1 (v:v). Após a emergência, efetuou-se o desbaste, deixando-se uma planta por vaso. Quinze dias após a semeadura, as plantas de tomateiro de cada vaso receberam $50 \mathrm{~mL}$ de solução nutritiva contendo, em mg L-1, 192 de $\mathrm{KCl}, 104,42$ de $\mathrm{K}_{2} \mathrm{SO}_{4}, 150,35$ de $\mathrm{MgSO}_{4} \cdot 7 \mathrm{H}_{2} \mathrm{O}, 61$ de uréia, 0,27 de $\mathrm{NH}_{4} \mathrm{MO}_{7} \mathrm{O}_{24} \cdot 4 \mathrm{H}_{2} \mathrm{O}$, 1,61 de $\mathrm{H}_{3} \mathrm{BO}_{3}, 6,67$ de $\mathrm{ZnSO}_{4}, 1,74$ de $\mathrm{CuSO}_{4} .5 \mathrm{H}_{2} \mathrm{O}, 4,10$ de $\mathrm{MnCl}_{2} \cdot 4 \mathrm{H}_{2} \mathrm{O}, 4,08$ de $\mathrm{FeSO}_{4} \cdot 7 \mathrm{H}_{2} \mathrm{O}$ e 5,58 de EDTA bisódico. A solução também foi aplicada na terceira e na quarta semana após semeadura. As plantas foram mantidas em casa de vegetação, onde a temperatura variou de 20 a $30^{\circ} \mathrm{C}$, e irrigadas diariamente.

\section{Pulverização dos indutores de resistência}

Plantas de tomateiro com a terceira folha, da base para o ápice, completamente expandida (33 dias após semeadura) foram pulverizadas com os indutores AJ (SigmaAldrich, São Paulo, SP), ET (Sigma-Aldrich, São Paulo, SP) e ASM (Bion ${ }^{\circledR}$, Syngenta, São Paulo, SP) nas concentrações de $0,1 \mathrm{mM}, 0,5 \mathrm{mM}$ e $0,3 \mathrm{~g} \mathrm{~L}^{-1}$, respectivamente, 48 horas antes da inoculação com Pst. Plantas pulverizadas com água destilada (AD) foram utilizadas como controle. Todas as folhas da planta da repetição de cada tratamento foram pulverizadas com $25 \mathrm{~mL}$ da solução dos indutores e também com AD. Posteriormente, as plantas foram mantidas em câmara de nevoeiro a $25^{\circ} \mathrm{C}$ e fotoperíodo de 12 horas de luz, onde permaneceram por 24 horas até serem inoculadas com Pst.

\section{Avaliação do período de incubação e do número de lesões da pinta bacteriana por planta}

Plantas de tomateiro foram inoculadas 48 horas após a pulverização da solução dos indutores e da $\mathrm{AD}$ com uma suspensão bacteriana na concentração de $1,0 \times 10^{8}$ UFC $\mathrm{mL}^{-1}$, com auxílio de atomizador De Vilbs no 15 . Às 24 horas após inoculação (hai), as plantas foram transferidas para casa de vegetação, onde a temperatura variou de 20 a $30^{\circ} \mathrm{C}$. Avaliou-se o período de incubação (PI) e o número de lesões (NL) da pinta bacteriana por planta nos cinco folíolos das folhas 1 e 2 totalmente expandidas, da base para o ápice, de cada planta. O PI (dias) foi avaliado a cada 24 hai e foi definido como o intervalo de tempo entre a inoculação e o aparecimento das lesões necróticas com halo clorótico. O NL por planta foi avaliado aos 15 dias após inoculação (dai).

Determinação da atividade das enzimas peroxidases (POX, EC 1.11.1.7), polifenoloxidases (PFO, EC 1.10.3.1), $\beta$-1,3-glucanases (GLU, EC 3.2.1.39) e lipoxigenases (LOX, EC 1.13.11.12)

Amostras das folhas 1 e 2 totalmente expandidas, da base para o ápice, das plantas de tomateiro das repetições de cada tratamento foram coletadas aos 2,6 , 9 e 12 dai. Amostras de folhas de plantas não inoculadas com Pst serviram como testemunha (0 dai). As amostras foram armazenadas individualmente em papel alumínio, rapidamente congeladas em nitrogênio $\left(\mathrm{N}_{2}\right)$ líquido e, em seguida, armazenadas em ultrafreezer a $-80^{\circ} \mathrm{C}$ para posterior análise. 
Para a obtenção dos extratos utilizados na determinação da atividade das enzimas POX, PFO e GLU, amostras de $0,3 \mathrm{~g}$ de tecido foliar foram maceradas com $\mathrm{N}_{2}$ líquido em almofariz com adição de polivinilpirrolidona (PVP) $1 \%(\mathrm{p} / \mathrm{v})$ até a obtenção de um pó fino. O pó obtido foi homogeneizado em tampão fosfato de sódio $50 \mathrm{mM}$, $\mathrm{pH}$ 6,5, contendo fluoreto de fenilmetilsulfônico (PMSF) 1 $\mathrm{mM}$. O homogeneizado foi centrifugado a $20.000 \times \mathrm{g}$ por 25 min a $4^{\circ} \mathrm{C}$ e o sobrenadante foi usado para as determinações enzimáticas. A atividade da POX foi determinada pela oxidação do pirogalol, de acordo com a metodologia de Kar \& Mishra (1976). A absorbância foi medida a $420 \mathrm{~nm}$ em espectrofotômetro (Evolution 60, Thermo Scientific, Waltham, MA, EUA) durante o período de 1 min após adição do extrato à mistura. $\mathrm{O}$ coeficiente de extinção molar de $2,47 \mathrm{mM}^{-1} \mathrm{~cm}^{-1}$ foi usado para calcular a atividade da POX (Chance \& Maehley, 1955), a qual foi expressa em $\mathrm{mM}$ de purpurogalina produzida por min $\mathrm{mg}^{-1}$ de proteína. A atividade da PFO foi determinada à semelhança da POX, exceto que o peróxido de hidrogênio não foi utilizado na mistura.

A atividade da GLU foi determinada conforme descrito por Lever (1972). A absorbância do produto liberado pela GLU foi medida a $540 \mathrm{~nm}$ e a atividade dessa enzima foi expressa em unidades de absorbância min $^{-1} \mathrm{mg}^{-1}$ de proteína.

Para a obtenção do extrato para determinação enzimática da LOX, 0,2 g de tecido foliar foi macerado com $\mathrm{N}_{2}$ líquido em almofariz. O pó obtido foi homogeneizado em tampão fosfato de sódio $20 \mathrm{mM}$ (pH 6,8) contendo Triton-X $1 \%(\mathrm{v} / \mathrm{v})$ e PVP $1 \%$. O homogeneizado foi centrifugado a $15.000 \times g$ por $10 \mathrm{~min}$ a $4^{\circ} \mathrm{C}$. O sobrenadante foi usado como extrato para determinação da atividade da LOX A atividade da LOX foi determinada conforme metodologia descrita por Axelrod et al. (1981). A absorbância do hidroperóxido de ácido linoléico liberado pela LOX foi medida em espectrofotômetro a $234 \mathrm{~nm}$. O coeficiente de extinção molar de $25.000 \mathrm{M}^{-1}$ $\mathrm{cm}^{-1}$ foi usado para determinar a atividade da LOX, a qual foi

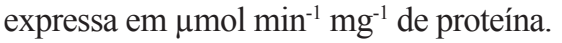

A concentração de proteínas em cada amostra foi determinada de acordo com o método colorimétrico descrito por Bradford (1976).

\section{Delineamento experimental e análises estatísticas}

Três experimentos foram instalados em delineamento inteiramente casualizado (DIC) com quatro tratamentos (plantas pulverizadas com AJ, ET, ASM e AD) e cinco repetições para avaliação do PI e do NL. Testes de Cochran e Bartlett não indicaram homogeneidade de variância para os três experimentos, os quais foram analisados separadamente. Os dados do PI e do NL foram submetidos à análise de variância (ANOVA) e as médias dos tratamentos comparadas pelo teste de Tukey ao nível de 5\% de probabilidade. Apenas um experimento foi realizado para obter amostras para as avaliações bioquímicas, o qual foi instalado em DIC com quatro tratamentos e três repetições. Os dados da atividade de POX, PFO, GLU e LOX foram submetidos à ANOVA e as médias dos tratamentos comparadas pelo teste de Tukey ao nível de $5 \%$ de probabilidade. Todas as análises foram realizadas utilizando-se o software SAS (SAS Institute, Inc., 1989, Cary, NC, EUA).

\section{RESULTADOS}

\section{Período de incubação e número de lesões da pinta bacteriana por planta}

Com relação ao PI, não houve diferença significativa entre os tratamentos nos Exps. 1 e 2 (Tabela 1). No Exp. 3, o PI aumentou significativamente em 1 dia nas plantas pulverizadas com ASM em relação ao controle (AD), embora sem diferir significativamente dos tratamentos AJ e ET (Tabela 1). Com relação ao NL por planta, houve diferença significativa entre os tratamentos AJ, ET e ASM em relação ao controle para todos os experimentos (Tabela 1). No Exp. 1, para as plantas pulverizadas com AJ, ET e ASM, houve redução significativa do NL por planta em 27,6; 42,5 e 28,9\%, respectivamente, em relação ao controle. No Exp. 2, não houve diferença significativa entre as plantas pulverizadas com AJ e ET e nem entre as plantas pulverizadas com ET e ASM (Tabela 1). No Exp. 2, para as plantas pulverizadas com AJ, ET e ASM, houve redução significativa para o NL por planta em 38,9; 45,3 e $68,1 \%$, respectivamente, em relação ao controle. No Exp. 3 , as plantas pulverizadas com AJ, ET e ASM apresentaram

TABELA 1 - Período de incubação (PI) e número de lesões (NL) por planta em tomateiros pulverizados com ácido jasmônico (AJ), etefon (ET), acibenzolar-S-metil (ASM) e água destilada (AD) e inoculados com Pseudomonas syringae pv. tomato

\begin{tabular}{llllllc}
\hline \hline \multirow{2}{*}{ Tratamentos } & \multicolumn{3}{c}{ PI (dias) } & \multicolumn{3}{c}{ NL por planta } \\
\cline { 2 - 6 } & Exp. 1 & Exp. 2 & Exp. 3 & Exp. 1 & Exp. 2 & Exp. 3 \\
\hline AJ & 6,0 & 6,0 & $5,6 \mathrm{ab}$ & $166,4 \mathrm{a}$ & $269,1 \mathrm{a}$ & $175,4 \mathrm{a}$ \\
ET & 6,0 & 6,1 & $5,6 \mathrm{ab}$ & $132,2 \mathrm{a}$ & $240,9 \mathrm{ab}$ & $193,9 \mathrm{a}$ \\
ASM & 6,4 & 5,4 & $6,0 \mathrm{a}$ & $163,2 \mathrm{a}$ & $140,6 \mathrm{~b}$ & $156,9 \mathrm{a}$ \\
AD & 6,1 & 5,8 & $5,0 \mathrm{~b}$ & $229,8 \mathrm{~b}$ & $440,4 \mathrm{c}$ & $353,9 \mathrm{~b}$ \\
Valores de F & $3,19^{\mathrm{ns}}$ & $1,83^{\mathrm{ns}}$ & $4,69^{* *}$ & $7,34^{* *}$ & $21,68^{* *}$ & $21,06^{* *}$ \\
\hline CV (\%) & 3,87 & 8,79 & 7,67 & 19,56 & 21,94 & 19,96 \\
\hline
\end{tabular}

$\mathrm{CV}=$ coeficiente de variação. Médias seguidas pela mesma letra, em cada coluna, não diferem estatisticamente $(P \leq 0,05)$ pelo teste de Tukey. ${ }^{n}$ $=$ não significativo. 
redução significativa do NL por planta em 50,4; 45,2 e $55,7 \%$, respectivamente, em relação ao controle (Tabela $1)$.

\section{Atividade das enzimas POX, PFO, GLU e LOX}

$\mathrm{O}$ AJ elevou significativamente a atividade da POX em relação ao controle a 6 e 12 dai (Figura 1A). Não houve diferença entre os tratamentos para a atividade da POX nas plantas não inoculadas com Pst (0 dai), bem como a 2 e 9 dai (Figura 1A). A atividade da PFO foi significativamente maior para as plantas pulverizadas com AJ a 0,6 e 12 dai e com o ASM a 0 e 6 dai em relação ao controle (Figura 1B). A atividade da PFO foi significativamente maior para as plantas pulverizadas com ET a 9 dai, em relação aos tratamentos ASM e controle. Não houve diferença significativa entre os tratamentos para a atividade da $\mathrm{PFO}$ a 2 dai (Figura 1B). Não houve diferença significativa entre os tratamentos AJ, ET e ASM e o controle quanto à atividade da GLU para as plantas não inoculadas com Pst (0 dai) (Figura 1C). A atividade da GLU foi significativamente maior para as plantas pulverizadas com AJ e ET, em relação ao controle, aos 2, 6, 9 e 12 dai (Figura 1C). A atividade da GLU foi significativamente maior nas plantas pulverizadas com o ASM apenas aos 6 e 12 dai (Figura 1C). Não houve diferença entre os tratamentos para a atividade da LOX nas plantas não inoculadas com Pst (0 dai), bem como aos 9 e 12 dai (Figura 1D). A atividade da LOX foi significativamente maior nas plantas pulverizadas com ASM em relação ao controle aos 2 e 6 dai e, para o ET, aos 2 dai (Figura 1D).

\section{DISCUSSÃO}

Os resultados deste estudo demonstram o efeito do AJ, ET e ASM na resistência do tomateiro quando infectado por Pst. O ASM prolongou o PI e também reduziu o NL por planta, confirmando que o ASM atuou na resistência do tomateiro contra um patógeno bacteriano. Scarponi et al. (2001) observaram que a pulverização de ASM nas folhas basais de tomateiro protegeu as folhas apicais contra a infecção por Pst. Estes autores verificaram que o ASM foi completamente degradado dentro da planta, conferindo proteção pela ativação de mecanismos de defesa. Assim, a redução na severidade da pinta bacteriana foi devido às condições no espaço intercelular que se tornaram desfavoráveis ao crescimento de Pst. Baysal et al. (2003) também demonstraram que tomateiro pulverizado com ASM
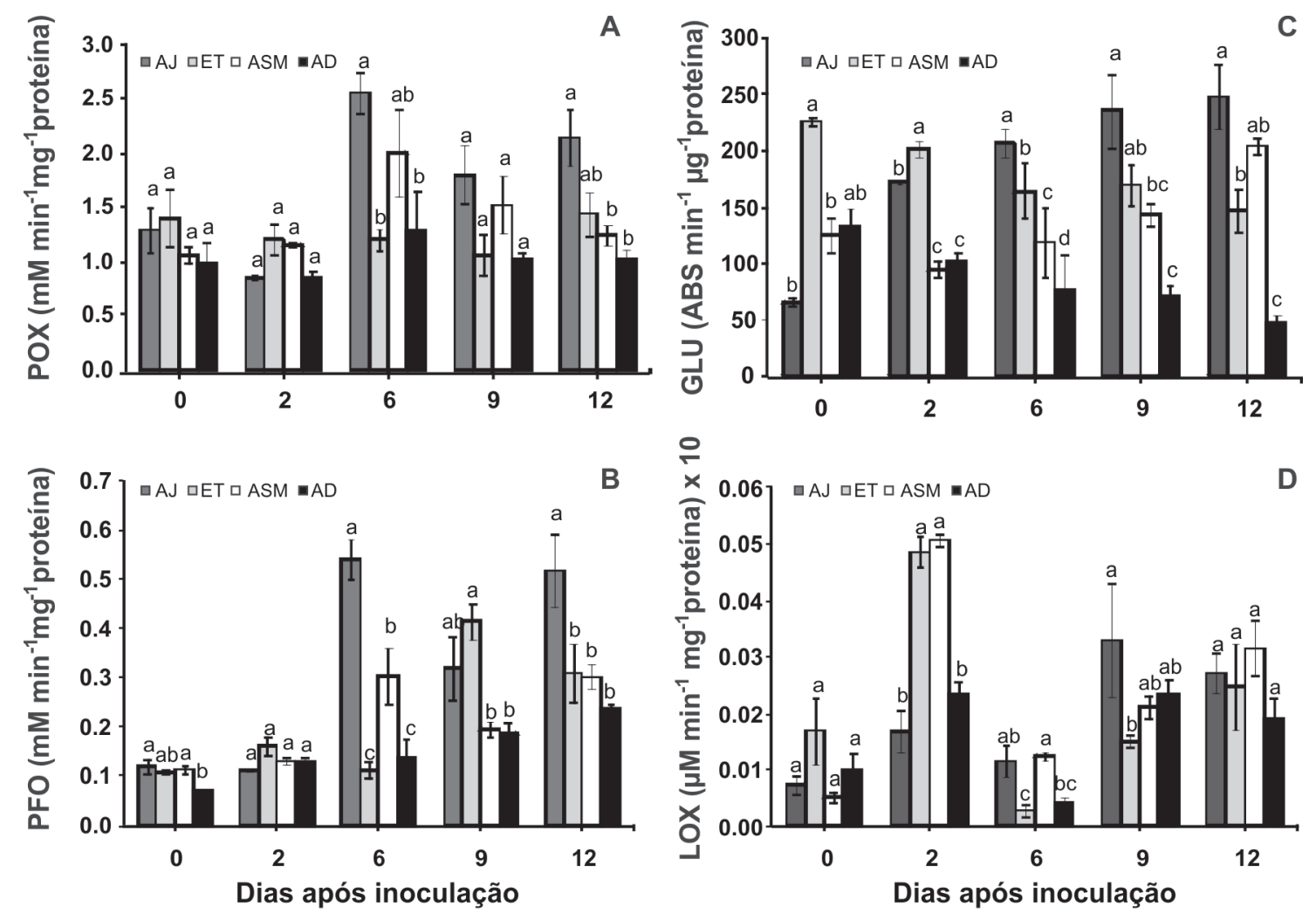

FIGURA 1 - A. Atividades de peroxidases (POX); B. polifenoloxidases (PFO); C. $\beta$-1,3-glucanases (GLU) e D. lipoxigenases (LOX) em folhas de tomateiro pulverizadas com ácido jasmônico (AJ), etefon (ET), acibenzolar-S-metil (ASM) e água destilada (AD) e inoculadas com Pseudomonas syringae pv. tomato. Médias dos tratamentos AJ, ET, ASM e AD seguidas pela mesma letra para cada época de avaliação não diferem pelo teste de Tukey ao nível de $5 \%$ de probabilidade. 
e inoculado com C. michiganensis subsp. michiganensis apresentou redução da severidade da pinta bacteriana.

Da mesma forma que para o ASM, houve redução do NL da pinta bacteriana quando as plantas foram pulverizadas com AJ e ET. Em plantas de Arabidopsis infectadas por Pst, o etileno modulou a resistência das plantas (Van Loon et al., 2006). Porém, pouco se conhece sobre o efeito do AJ e do ET nas interações compatíveis envolvendo patógenos bacterianos. Entretanto, os sintomas do míldio pulverulento em videira (Erysiphe necator) foram reduzidos com a pulverização de metil jasmonato (Belhadg et al., 2006) e ET (Belhadg et al., 2008).

As defesas das plantas são reguladas por complexas rotas de sinalização envolvendo o AJ, ET e o AS (Kunkel \& Brooks, 2002). O AJ atua como indutor de resistência por estimular a produção de compostos de defesa, como terpenóides, e ativar genes que codificam para a expressão de enzimas, como peroxidases e polifenoloxidases (Thaler, 1999). Entretanto, trabalhos demonstrando o efeito da pulverização do metil jasmonato na atividade de enzimas relacionadas à defesa do tomateiro a Pst são inexistentes. Porém, Pieterse et al. (1998) verificaram que plantas de Arabidopsis pulverizadas com metil jasmonato tornaram-se mais resistentes à infecção por Pst. No presente trabalho, um dos possíveis mecanismos envolvidos na resistência do tomateiro mediado pelo AJ pode ser atribuído ao fato de que Pst produz a toxina coronatina que atua de forma análoga ao AJ (Feys et al., 1994). Mittal \& Davis (1995) verificaram que esta toxina pode ter efeito direto na expressão de genes envolvidos na resistência das plantas a patógenos.

Plantas pulverizadas com AJ e inoculadas com Pst apresentaram maior atividade da POX e PFO, assim como plantas pulverizadas com ASM e não inoculadas com Pst. Aos 6 dai ocorreu o aparecimento dos primeiros sintomas da pinta bacteriana, de modo que o tomateiro, na tentativa de conter a infecção por $P s t$, aumentou a atividade dessas duas enzimas. Este aumento foi maior até 12 dai. A POX está relacionada com o processo de proteção antioxidativa, o qual promove o aumento na síntese de lignina que fortalece a parede celular contra a ação de enzimas líticas produzidas pelos patógenos (Kvaratskhelia et al., 1997). A PFO é responsável pela formação de quinonas, as quais apresentam atividade antimicrobiana (Mayer \& Staples, 2002). Ngadze et al. (2011) também relacionaram o aumento na atividade da POX e da PFO com a maior resistência de tubérculos de batata a Pectobacterium atrosepticum, P. carotovorum subsp. brasiliensis e Dickeya spp. Li \& Steffens (2001) verificaram que uma maior atividade da PFO resultou em aumento da resistência de tomateiros transgênicos a Pst.

A ativação de enzimas de defesa pelo ASM foi verificada em diversos trabalhos. De acordo com Cavalcanti et al. (2006a), a atividade da POX foi induzida em tomateiro pulverizado com ASM e inoculado com $X$. campestris pv. vesicatoria. Baysal etal.(2003) também verificaram que plantas de tomateiro pulverizadas com ASM apresentaram maior atividade da POX quando infectadas por C. michiganensis subsp. michiganensis.

A GLU é responsável pela degradação da parede celular de patógenos fúngicos, contribuindo para a geração de elicitores com potencial para ativar respostas de defesa das plantas (Mohammadi et al., 2002). No entanto, a função desta enzima hidrolítica na resistência de plantas à infecção por patógenos bacterianos ainda é pouco conhecida (Cavalcanti et al., 2006b). No presente trabalho, aumento significativo das GLU foi observado durante todo o processo infeccioso de Pst em plantas pulverizadas com AJ e ET e a partir dos 6 dai, para o ASM. Sabe-se que o ET pode ativar a percepção da planta ao ataque de patógenos, promovendo a ativação de mecanismos de defesa (Boller, 1991). Aumento na atividade desta enzima também foi relatado em tomateiro pulverizado com ASM e inoculado com $X$. campestris pv. vesicatoria (Cavalcanti et al., 2006b). A GLU também foi relacionada com a indução de resistência em tomateiro inoculado com Pst e pré-tratado com Methylobacterium oryzae (Indiragandhi et al., 2008).

A LOX catalisa a oxigenação de ácidos graxos, como o ácido linoleico, em hidroperóxidos (Axelrod et al., 1981). Verificou-se maior atividade da LOX nas plantas pulverizadas com ET aos 2 dai e com ASM aos 2 e 6 dai. Maior atividade da LOX foi importante na redução dos sintomas da pinta bacteriana. Resultados semelhantes foram encontrados por Koch et al. (1992) ao observarem maior atividade da LOX em tomateiro infectado por Pst e P. syringae pv. syringae.

Os resultados deste estudo demonstram que a aplicação dos indutores AJ, ET e ASM aumentaram a resistência do tomateiro à infecção por $P s t$, principalmente pelo aumento em atividade das enzimas POX, PFO, GLU e LOX.

\section{AGRADECIMENTOS}

À Sakata Seed Sudamerica e à Syngenta Proteção de Cultivos Ltda., pelo fornecimento, respetivamente, das sementes de tomateiro e do Bion. Ao Conselho Nacional de Desenvolvimento Científico e Tecnológico - CNPq, pela concessão de bolsa de produtividade em pesquisa aos Professores F.A. Rodrigues e R.L.R. Mariano. A Alberto, Henrique e Éder, pelo auxílio nas análises estatísticas.

\section{REFERÊNCIAS BIBLIOGRÁFICAS}

Axerold B, Chessbrough TM, Laakso S (1981) Lipoxygenase from soybeans. Methods in Enzymology 71:441-451.

Baysal O, Soylu EM, Soylu S (2003) Induction of defence-related enzymes and resistance by the plant activator acibenzolar-Smethyl in tomato seedlings against bacterial canker caused by Clavibacter michiganensis subsp. michiganensis. Plant Pathology 52:747-753. 
Belhadj A, Saigne C, Telef N, Cluzet S, Bouscaut J, Corio-Costed MF, Mérillon JM (2006) Methyl jasmonate induces defense responses in grapevine and triggers protection against Erysiphe necator. Journal of Agricultural and Food Chemistry 54:91199125.

Belhadj A, Telef N, Cluzet S, Bouscaut J, Corio-Costed MF, Mérillon JM (2008) Ethephon elicits protection against Erysiphe necator in grapevine. Journal of Agricultural and Food Chemistry 56:5781-5787.

Boller T (1991) Ethylene in pathogenesis and disease resistance. In: Mattoo, AK, Suttle, JC (Eds.) The plant hormone ethylene. Boca Raton FL, EUA. CRC Press. pp. 293-314.

Bradford MN (1976) A rapid and sensitive method for the quantitation of microgram quantities of protein utilizing the principle of protein-dye binding. Analytical Biochemistry 72:248254.

Cavalcanti FR, Resende MLV, Lima JPMS, Silveira, JAG, Oliveira, JTA (2006a) Activities of antioxidant and photosynthetic responses in tomato pre-treated by plant activators and inoculated by Xanthomonas vesicatoria. Physiological and Molecular Plant Pathology 68:198-208.

Cavalcanti FR, Resende MLV, Pereira RB, Costa JCB, Carvalho CPS (2006b) Atividades de quitinase e beta-1,3-glucanase após eliciação das defesas do tomateiro contra a mancha bacteriana. Fitopatologia Brasileira 41:1721-1730.

Chance B, Maehley AC (1955) Assay of catalases and peroxidases. Methods in Enzymology 2:764-775.

Feys BJF, Benedetti CE, Penfold CN, Turner JG (1994) Arabidopsis mutants selected for resistance to the phytotoxin coronatine are male sterile, insensitive to methyl jasmonate, and resistant to a bacterial pathogen. Plant Cell 6:751-759.

Görlach J, Volrath S, Knauf Beiter G, Hengy G, Beckhove U, Kogel KH, Oostendorp, M, Staub T, Ward E, Kessmann H (1996) Benzothiadiazole, a novel class of inducers of systemic resistance, actives gene expression and disease resistance in wheat. Plant Cell 8:629-643.

Indiradandhi PI, Anandham R, Kim K, Yim W, Madhaiyan M, AS T (2008) Induction of defense responses in tomato against Pseudomonas syringae pv. tomato by regulating the stress ethylene level with MethylobacteriumoryzaeCBMB20 containing 1-aminocyclopropane1-carboxylate deaminase. Journal of Microbiology and Biotechnology 24:1037-1045.

Kado CI, Heskett MG (1970) Selective media for isolation of Agrobacterium, Corynebacterium, Erwinia, Pseudomonas and Xanthomonas. Phytopathology 60:969-976.

Kar M, Mishra D (1976) Catalase, peroxidase and polyphenoloxidase activities during rice leaf senescence. Plant Physiology 57:315-319.

Koch E, Meier BM, Eiben HG, Slusarenko A (1992) A lipoxygenase from leaves of tomato (Lycopersicon esculentum Mill.) is induced in response to plant pathogenic Pseudomonads. Plant Physiology 99:571-576.

Kunkel BN, Brooks DM (2002) Cross talk between signaling pathways in pathogen defense. Current Opinion in Plant Biology 5:325-331.

Kvaratskhelia M, Winkel C, Thorneley RNF (1997) Purification and characterization of a novel class of peroxidase isoenzyme from tea leaves. Plant Physiology 114:1237-1245.
Lamb C, Dixon RA (1997) The oxidative burst in plant disease. Annual Review of Plant Physiology 48:251-275.

Lever M (1972) A new reaction for colorimetric determination of carbohydrates. Analytical Biochemistry 47:273-279.

Li L, Steffens C (2001) Overexpression of polyphenoloxidase in transgenic tomato plants results in enhanced bacterial disease resistance. Planta 215:239-247.

Mariano RLR, Assis SMP (2005) Identificação de bactérias fitopatogênicas. In: Mariano RLR, Silveira EB (Eds.) Manual de práticas em Fitobacteriologia. $2^{\text {a }}$ Ed. Recife PE. Universidade Federal Rural de Pernambuco. pp. 67-109.

MAPA - Ministério da Agricultura, Pecuária e Abastecimento (2007). Agrofit - Sistemas de Agrotóxicos Fitossanitários. Disponível em: http://www.agricultura.gov.br/agrofit. Acesso em 26 de fevereiro de 2012.

Mayer AM, Staples RC (2002) Laccase: New functions for an old enzyme. Phytochemistry 60:551-565.

Mittal S, Davis KR (1995) Role of the phytotoxin coronatine in the infection of Arabidopsis thaliana by Pseudomonas syringae pv. tomato. Molecular Plant-Microbe Interactions 8:165-171.

Mohammadi M, Roohparvar R, Torabi M (2002) Induced chitinase activity in resistant wheat leaves inoculated with an incompatible race of Puccinia striiformis f. sp. tritici, the causal agent of yellow rust disease. Mycopathologia 154:119-126.

Ngadze E, Icishahayo D, Coutinho TA, van der Waals JE (2011). The role of polyphenol oxidase, peroxidase, phenylalanine ammonia lyase, chlorogenic acid and total soluble phenols in the resistance of potatoes to soft rot. Plant Disease 96:186-192.

Pieterse CMJ, Van Wees SCM, Van Pelt JÁ, Knoester M, Laan R, Gerrits H, Weisbeek PJ, Van Loon LC (1998) A novel signaling pathway controlling induced systemic resistance in Arabidopsis. Plant Cell 10:1571-1580.

Scarponi L, Buonaurio R, Martinetti L (2001) Persistence and translocation of a benzothiadiazole derivative in tomato plants in relation to systemic acquired resistance against Pseudomonas syringae pv. tomato. Pest Management Science 57:262-268.

Schaad NW (1988) Laboratory Guide for Identification of Plant Pathogenic Bacteria, $2^{\text {nd }} E d$. Saint Paul MN, EUA. APS Press.

Silva VL, Lopes CA (1995) Populações epifíticas de Pseudomonas syringae pv. tomato em cultivo comercial de tomateiro industrial. Fitopatologia Brasileira 20:179-183.

Silva MAS, Carmo MGF, Olivares FL, Pereira AJ (2002) Termoterapia via calor seco no tratamento de sementes de tomate: eficiência na erradicação de Xanthomonas campestris pv. vesicatoria e efeitos sobre a semente. Fitopatologia Brasileira 27:586-593.

Stockinger EJ, Walling LL (1994) Pto3 and Pto 4: Novel genes from Lycopersicon hirsutum var. glabrattum that confer resistance to Pseudomonas syringae pv. tomato. Theoretical and Applied Genetics 89:879-994.

Thaler JS (1999) Induced resistance in agricultural crops: Effects of jasmonic acid on herbivory and yield of tomato plants. Environmental Entomology 28:30-37.

Van Loon LC (1997) Induced resistance in plants and the role of pathogenesis-related proteins. European Journal of Plant Pathology 103:753-765. 


\section{C.C.L. Andrade et al.}

Van Loon LC, Geraats BPJ, Linthorst JM (2006) Ethylene as a modulator of disease resistance in plants. Plant Science 11:184-191.

Yahia A, Kevers C, Gaspar T, Chénieux JC, Rideau M, Créche
J (1998) Cytokinins and ethylene stimulate indole alkaloid accumulation in cell suspension cultures of Catharanthus roseus by two distinct mechanisms. Plant Science 133:9-15.

TPP 565 - Recebido 29 Março 2012 - Aceito 18 Setembro 2012 Editor de Seção: Andréa B. Moura 